\title{
Analysis of fouling development under dynamic membrane filtration operation
}

Mubashir Saleem ${ }^{a}$, Luca Alibardi ${ }^{b}$, Raffaello Cossu ${ }^{c}$, Maria Cristina Lavagnolo ${ }^{c}$, Alessandro Spagni $^{\mathrm{d}}$

${ }^{\text {a }}$ Department of Civil, Environmental and Architectural Engineering, University of Padova, via Marzolo 9, 35131 Padova, Italy

${ }^{\mathrm{b}}$ Cranfield Water Science Institute, Cranfield University, Bedford, MK43 0AL, UK

${ }^{\mathrm{c}}$ Department of Industrial Engineering, University of Padova, via Marzolo 9, 35131 Padova, Italy

${ }^{\mathrm{d}}$ Laboratory of Technologies for Waste, Wastewater and Raw Materials Management, Italian National Agency for New Technologies, Energy and Sustainable Economic Development (ENEA), via M.M. Sole 4, 40129 Bologna, Italy

\section{* Corresponding author:}

Luca Alibardi

Cranfield Water Science Institute, Cranfield University, Bedford, MK43 0AL, UK

Email: 1.alibardi@cranfield.ac.uk 


\section{Abstract}

This research is a contribution towards evaluating the appropriate fouling mechanism responsible for the flux decline under dynamic membrane (DM) filtration and its formation mechanism by using gravity-driven filtration in a specifically design experimental setup. Series of extended short term filtration experiments were performed at varying operating conditions of mixed liquor suspended solids (MLSS) concentrations, trans-membrane pressures (TMP) and mesh pore sizes. Blocking models were applied to identify the fouling mechanisms occurring in DM development. The results demonstrated that cake filtration model can adequately describe fouling mechanisms during DM filtration. According to the Analysis of variance, DM development, as described by flux $(J)$ trends during filtration, was significantly affected by TSS MLSS concentration only while effluent turbidity was significantly affected by MLSS concentration and TMP. On the contrary, $J$ and effluent turbidity trends during filtration were not significantly influenced by mesh pore size, at least in the range used in this study $(10-200 \mu \mathrm{m})$.

Keywords: Dynamic membrane, Fouling modelling, Mesh filtration, Curve fitting, Gravity driven filtration. 


\section{Introduction}

The use of membranes in wastewater treatment is finding growing application due to their complete solid retention, flexibility in operation and small footprints. However, high capital and operating cost and inevitable fouling phenomenon hinders their extensive application [1]. In this regard, dynamic membranes (DMs) represent an attractive alternative to the use of conventional microfiltration and ultrafiltration (MF/UF) membranes by positively employing the fouling cake as a mean for solid liquid separation [2-4]. DM is a fouling surface that is formed by the deposition of suspended solids, colloids or microbial cell particles over an underlying support material (meshes, filter cloth etc.) [4-8]. Meshes of different porosity ranging from 10 to $500 \mu \mathrm{m}$ have been reported in literature as a suitable support material for developing DMs [7-10]. The filtration mechanism of DMs is quite different to conventional MF/UF membranes in a way that, after the formation of DM layer, the filtration resistance is exclusively caused by the cake layer [7]. However, an excessive growth of a thick and dense fouling layer hinders a long term filtration operation due to excessive loss of permeability $[2,12]$. Therefore, the identification of operating parameters (e.g. nature and characteristics of the constituting particles, underlying support, suspended solids concentration, mesh pore sizes and hydrodynamic conditions) affecting the DM development remains crucial for practical large scale applications [3, 12-15] but the management of these parameters to ensure performance reproducibility and control of transmembrane pressure (TMP) still represents a challenging task for DM implementation. Mathematical modelling is a useful tool that has been widely applied to analyse fouling in conventional membranes. Four models have been proposed to assess the fouling evolution over time in the form of complete blocking, intermediate blocking, standard blocking and cake filtration models. Complete pore blocking mechanism takes the assumption that the particles reaching the membrane surface block membrane pores without superposing other particles 
whereas, in intermediate blocking mechanism particles have an equal probability to deposit on other particles that ultimately cause pore blocking. Standard blocking, assumes that the particles deposit on the pore inner surface that gradually leads to pore constriction and ultimately to pore blocking. Cake formation mechanism is based on the assumption that particles reaching the membrane surface are larger than the membrane pore size and hence, they do not block them, rather form a layer on the membrane surface.

Hermia [17] derived mathematical equations describing flux evolution over time under constant pressure filtration for these four blocking mechanisms (Table 1).

Some authors have stated that the fouling process could also be governed by a combination of these mechanisms occurring simultaneously or at different stages during a filtrations operation depending upon the characteristics of the membrane, feed and operating parameters like filtration flux $(J)$ and TMP [18-22].

These models [17] have found several applications in studying the fouling mechanisms in conventional membrane filtration, andalthough fouling processes play a decisive role in DM development, very few authors have tried to specifically understand how these phenomena occur in DMs by model-based analyses [6, 7]. In fact, to the best knowledge of the authors, no studies have been performed yet to specifically evaluate the fouling development in DM by using mathematical modelling and, in particular, if the fouling models developed for membrane filtration can also be applied for DMs. Furthermore, the use of mathematical modelling to elucidate the formation mechanism of DMs in conjunction with the effect of changes in operating conditions (TMP and suspended solids concentration) on model response and its interpretation is still limited.

To date, studies have mainly been focused on evaluating the effect of different operating conditions and process variables on the development and performance of DM $[2,3,8-15,23$, 24], while very few studies have discussed the mechanism governing the formation of DMs [5- 
7]. To the best knowledge of the authors, there is a lack of information about the effect of changing parameters on the mechanisms involved in DM formation.

The aim of this study is to understand the main mechanisms governing DM formation and to evaluate the possible effects of variation of operating parameters on DM development and performance. Filtration tests were carried out with a set of diverse operating conditions in a specifically designed experimental set-up. The results obtained from these experiments were analysed by blocking models proposed by Hermia [17] to predict the most likely fouling mechanism occurring in DM filtration.

\section{Materials and methods}

\subsection{Experimental setup}

The study was conducted at laboratory-scale in a specifically designed apparatus (Figure 1). The experimental setup consisted of a $10 \mathrm{~L}$ stirring tank connected to an external filtration vessel by means of a peristaltic pump (Watson-Marlow 604U, Italy). The contents of the stirring tank were kept completely mixed by using an overhead stirrer (LS F201A0151, VELP Scientifica, Italy) operating at $200 \mathrm{rpm}$. The filtration vessel was made from a $1 \mathrm{~mm}$ thick Plexiglas tube having an internal diameter of $42 \mathrm{~mm}$ and a length of $180 \mathrm{~mm}$. The filtration module contains a nylon mesh wound over a cylindrical support made of plastic with an external diameter of $35 \mathrm{~mm}$ and a length of $68 \mathrm{~mm}$. The openings $(6 \mathrm{~mm} \times 5 \mathrm{~mm})$ of the supporting cylinder were uniformly distributed with an effective filtration area of $58.3 \mathrm{~cm}^{2}$. The cylindrical support was placed concentric to the filtration vessel in order to maintain a uniform hydraulic regime around the mesh surface. The stirring tank was filled with anaerobic sludge with total solids (TS)

concentration of $12.3 \mathrm{~g} \mathrm{~L}^{-1}$ and volatile solids (VS) concentration of $7.13 \mathrm{~g} \mathrm{~L}^{-1}$ respectively. The 
sludge was collected from a full-scale mesophilic sludge digester treating the excess sludge of the municipal wastewater treatment plant of Padova, Italy. The required MLSS concentration was then attained by concentrating the sludge through settling or diluting by adding the supernatant of the same sludge.

\subsection{Filtration experiments}

A series of short term filtration experiments were performed at different operating conditions of mesh pore sizes, mixed liquor suspended solids (MLSS) and TMP. Five different mesh pore sizes $(10,52,85,135,200 \mu \mathrm{m})$ were tested at three different MLSS concentrations $(4,8,15 \mathrm{~g} / \mathrm{L})$ and three different TMPs $(5,10,18 \mathrm{kPa})$. Details of the polyamide nylon meshes used in this study are reported in Table 2. Combination of these parameters was organised in a set of 45 experiments (Table S1, supplementary material), each lasting for $5 \mathrm{~h}$. Constant pressure gravitydriven filtration mode was employed. Each experiment was performed at constant TMP provided by the hydrostatic water head maintained above the filtration module. Permeate and concentrate were recirculated to the stirring tank in order to maintain (almost) constant the MLSS (with the exception of the very small samples collected for analysis and of the mass of solids forming the dynamic layer); the volume of the stirring tank $(10 \mathrm{~L})$ was chosen large enough in order to make negligible the effect of solids loss during sampling and DM layer formation on the MLSS concentration.

A constant cross flow velocity (CFV) of $30 \mathrm{~m} \mathrm{~h}-1$ was maintained by the MLSS recirculation in all the experimental runs. The application of cross-flow was necessary to avoid possible sedimentation of the sludge inside the external module that could affect the MLSS concentration close to the mesh support [9]. The applied CFV in this study was anyway two-three orders of magnitude lower than the values usually applied in conventional membrane filtration [4] and it 
was maintained as low as possible to reduce the effect of hydraulic shear on the developing DM layer and to maintain the hydraulic regime as close as possible to dead-end filtration mode. Although blocking models were derived for dead-end filtration system, the effect of hydraulic shear generated by the very low CFV applied in this study was considered negligible therefore, these models are applied to assess dynamic filtration development and performance. Geissler and Werner [25] observed in fact that at low CFV the behaviour of fouling resistance in both crossflow filtration and dead-end filtration was similar under similar operational conditions for conventional membranes.

Filtration flux was calculated by measuring the time to collect a known volume of permeate by using a graduated cylinder. Effluent samples were collected at regular intervals and analysed for total suspended solids (TSS) concentration and turbidity. TSS in the stirring tank were measured before and after every experimental run to ensure constant concentration. TSS were measured according to Standard Methods [26]. Turbidity measurements were performed by using a turbidimeter (2100P, HACH).

\subsection{Data analysis}

Curve fitting of the experimental observations was performed with classical constant-pressure dead-end filtration equations proposed by Hermia [17] and reported in Table 1. More precisely, filtration flux $(J)$ versus filtration time data was plotted and fitted in a Microsoft Excel worksheet. Sum of squared errors (SSE) between numerical predictions and experimental observation was calculated and minimised to optimise the parameters $K_{b}, K_{s}, K_{i}, K_{c}$ for every experimental run using the Solver add-in of Microsoft Excel. To evaluate accurate model prediction for the observed data, two statistical indices, root-mean-square error (RMSE) and adjusted coefficient of determination $\left(\mathrm{R}_{\text {adj }}^{2}\right)$, were used. The former statistical index shows the spread of errors between modelled and observed data while the latter is used as a measure of the 
strength of linear dependence between modelled and experimental observations. RMSE was preferred over other estimation of residuals, such as the sum of square and the mean square error, since it returns results in the same units of the models.

In order to assess the effect of the applied operating condition and their interactions on the filtration behaviour, factorial analysis of variance (ANOVA) considering two-way interaction between parameters was performed by using IBM SPSS Statistics software on measured $J$ and effluent turbidity values after specific time intervals of continuous filtration. Moreover, ANOVA was also applied on the optimised values of blocking constants $(K)$ for the model that best fits the experimental data.

Due to the short duration of the experiment in this study (i.e. $5 \mathrm{~h}$ ), the four basic fouling models (Table 1) were independently applied as the aim of this study was to assess the effect of operating conditions on fouling mechanism and DM filtration performance. This approach is different to the other studies where combinations of fouling mechanisms were also applied [6, 7, 18 ] but it has been reported that combined models, although can improve data fit, could result in inaccurate estimation of model parameters [18].

Regression analysis of $J$ values measured at the end of the experiments $v s$ different mesh porosities used in this study was also carried out using IBM SPSS Statistics software.

\section{Results and Discussion}

\subsection{Flux trends}

Flux profiles of dynamically formed membrane in all experiments demonstrated a similar decreasing trend, irrespective of the variations in operating conditions (Figure 2). These trends were similar to the flux decline trend observed for conventional MF/UF membranes during dead- 
end filtration at constant TMP with a sharp decline in first few minutes, followed by a much gradual decline in the later stages of the experiment. However, a significant difference was observed in the magnitude of initial filtration flux and its rate of decline which were much higher as compared to conventional membranes [27]. This behaviour was due to the difference in pore size between conventional membranes and the nylon meshes used in this study. In fact, the results showed very high initial filtration fluxes, ranging from 329 to $9880 \mathrm{Lm}^{-2} \mathrm{~h}^{-1}$ depending upon the applied operating conditions. Nevertheless, the following rapid increase of the filtration resistance (i.e. decrease of $J$ ) demonstrated the rapid development of the DM (within few minutes of filtration). As a matter of fact, fluxes reduced to less than $20 \%$ of their initial values $\left(J_{o}\right)$ after only 4 minutes of filtration, and later on it further reduced to around 0.2 to $2 \%$ of $J_{o}$ at the end $(5 \mathrm{~h})$ of each experimental run (Figure 2$)$. Due to these high variations in the filtration flux values the ratio between the retentate and the permeate greatly varied throughout a single experiment and also under different operating conditions applied in this study. However, after 90 minutes of continuous filtration the fluxes reduced to almost $90 \%$ of their initial flux values for all the experiments and the retentate to permeate ratio after this time interval was fairly constant averaging around $158 \pm 6.4$.

Figure 2 also illustrates three distinct levels of flux profiles grouped together with respect to three different MLSS concentrations used in this study. Therefore, it can be observed that higher MLSS concentration tend to increase the rate of fouling, reducing filtration fluxes right from the beginning of the filtration test. Thus, the highest MLSS concentration showed the lowest values of $J_{0}$ (i.e. measured over the first min of filtration). The influence of MLSS concentration on fouling development is also clearly evident by observing the trend in flux decline. In fact, as a general behaviour, the higher the MLSS concentration, the lower the filtration flux (Figure 2). On the contrary, the effect of TMP and pore size cannot be clearly identified by looking at the flux profiles (Figure 2). 
To support this argument, the final values of the flux measured at the end of the 45 experiments were compared (Figure 3). Fouling development could be considered as an evolutionary process and thus final values of filtration fluxes carry the history of the fouling process and represent the effect of operating parameters on the filtration characteristics of DMs (Figure 3). Small variations on final fluxes can be observed for experiments at same MLSS but different TMPs and mesh porosities, with the exception for the trends measured using low MLSS concentration (i.e. 4g/L) at high TMP value (i.e. $18 \mathrm{kPa}$ ) where with increasing mesh pore size seems to favour higher final (after $5 \mathrm{~h}$ ) filtration flux values (Figure 3c). Linear regression analysis of final fluxes $v s$ pore size confirms that data obtained by TMP $18 \mathrm{kPa}$ and $4 \mathrm{~g} / \mathrm{L}$ of MLSS returns a slope $\left(\mathrm{s}=0.0953 \mathrm{~L} \mathrm{~m}^{-2} \mathrm{~h}^{-1} \mu \mathrm{m}^{-1}=95,344 \mathrm{~L} \mathrm{~m}^{-3} \mathrm{~h}^{-1}\right.$ ) significantly different to zero $(\mathrm{p}=0.026)$ while all other regressions have slopes that are not significantly different to zero (data not showed). Therefore, results suggest that pore size seems not to affect the final (i.e. after $h$ ) filtration fluxes with the exception of sludge with low suspended solids concentration at high pressure.

Contrary to the results obtained in this study, Salerno et al. [28] found that the mesh pore size (20 and $50 \mu \mathrm{m}$ ) significantly affected the permeate characteristics and flux while operating a bench-scale aerobic dynamic membrane bioreactor. However, their system was operated very differently to the conditions used during the experiments in this study (e.g. constant flux instead of constant pressure, air scouring to control the cake layer). Therefore, while the mesh pore size does not affect the permeate flux in well-defined operating conditions as those applied in the present study, the support material could, however, affect the permeate characteristics for different filtration systems.

The observation that low MLSS concentration at high TMP, is favourable for high filtration fluxes is in agreement with the observation made by Li et al. [29], who, however, applied TMPs up to $0.62 \mathrm{kPa}\left(63 \mathrm{~mm}-\mathrm{H}_{2} \mathrm{O}\right)$, which is much smaller as compared to the values applied in this study. 


\subsection{Curve fitting estimation of fouling models}

Curve fitting analyses of fluxes obtained from filtration experiments suggest that cake filtration model best describes the fouling behaviour in DMs while imperfect agreements of intermediate and standard blocking models with experimental data were observed. An example is reported in Figure 4 for results obtained for the experiment at $4 \mathrm{~g} / \mathrm{L} \mathrm{MLSS}, 5 \mathrm{kPa}$ TMP and with $10 \mu \mathrm{m}$ mesh pore size. In most of the experiments the observed data seem to have reasonable agreement with modelled results shown by the measured $\mathrm{R}_{\text {adj }}^{2}$ values which, excluding the complete blocking model, were always above 0.94 (Figure S1, supplementary material). These results are also confirmed by the RMSE values, which are the highest for pore blocking models and the lowest for cake filtration model (Figure S3, supplementary material). However, the efficiency of the four models in describing the experimental varied at changing operating conditions.

\subsubsection{Complete blocking analysis}

The result of curve fitting with complete blocking model usually showed poor data fits between predicted and experimental values (Figure 4) as depicted by high RMSE values (Figure S3, supplementary materials). It implies that fouling mechanism in DM filtration was not a result of complete pore blocking by the particles reaching the mesh surface. Although this model failed to depict fouling development in DMs, RMSE values changed with varying operating conditions and the lowest values were observed for experiments with smaller pore size meshes $(10 \mu \mathrm{m})$ and high MLSS concentration (15 g L-1) (Figure S2, supplementary material).

Although complete blocking model showed the lowest efficiency in fitting the experimental data, it is of note that $\mathrm{R}_{\text {adj }}^{2}$ often achieved values higher than 0.90 (Figure $\mathrm{S} 1$, supplementary material), demonstrating that even this model can reasonable describe the fouling occurrence in DMs. 


\subsubsection{Standard blocking analysis}

Curve fitting of the experimental data obtained during this study by using the standard blocking model was not completely satisfactory (Figure 4). Li et al. [6] assumed standard blocking fouling to be the major blocking mechanism at the initial stage of DM filtration by reasoning that due to large difference between mesh pore and particle size, all other blocking mechanisms were improbable and thus fouling would be initiated by particle adhesion. However, model response observed in this study do not support this hypothesis particularly at lower MLSS, higher TMP and high mesh porosity as represented by high RMSE values (Figure S2, supplementary material).

It was observed that the effect of MLSS concentration on model response seemed more prominent as compared to TMP and mesh porosity. This is highlighted by comparing average RMSE values at 4, 8 and $15 \mathrm{~g} / \mathrm{L}$ of MLSS concentration which were 122, 55 and $24 \mathrm{Lm}^{-2} \mathrm{~h}^{-1}$, respectively (Figure S2, supplementary materials), suggesting that the standard blocking model improves the description of the experimental data increasing suspended solids concentration.

\subsubsection{Intermediate blocking analysis}

Model predictions made by intermediate blocking model were in much better agreement with the experimental data as compared to complete pore blocking and standard blocking models for the experimental conditions tested during this study (Figure 4). As for standard blocking models, the value of RMSE obtained by using intermediate-blocking fouling model tends to reduce with the increase in MLSS concentration and decrease in mesh pore size (Figure S2, supplementary materials).

\subsubsection{Cake filtration analysis}


Cake filtration model shows the best fit of the experimental data during DM filtration (Figure 4) as confirmed by the highest $\mathrm{R}_{\text {adj }}^{2}$ (usually $>0.99$ ) and the lowest RMSE values (Figures $\mathrm{S} 1$ and S2, supplementary materials). Therefore, the model analysis of the main fouling models confirms that the assumption of cake filtration model (i.e. a cake layer that can act as a solid-liquid separation medium) is actually valid in describing the behaviour of the flux trends in DM development and filtration. DM filtration through a cake layer is also different from conventional microfiltration membranes because in later case the initial rapid flux decline is mainly due to pore constriction (standard blocking) caused by the particle deposition on the walls of the membrane followed by a slower flux decline due to cake formation over the membrane surface $[30]$.

The response of cake filtration model on varying operating conditions showed (as for the other fouling model) a similar trend of decreasing RMSE with an increase in MLSS concentration. It follows, therefore, that the model slightly deviated from ideal cake filtration behaviour at low MLSS concentration. This effect is confirmed by studies on conventional MF/UF membranes indicating that membrane fouling and cake formation is enhanced at high MLSS concentration [31].

The effect of the applied operating conditions (i.e. TMP, pore size and MLSS concentration) was evaluated by ANOVA. The statistical analysis was performed on the optimised values of cake blocking constants $(K c)$ since the results of curve fitting supported cake filtration model to be the governing fouling mechanism in DM filtration. ANOVA analysis demonstrated that MLSS concentration proved to have the most significant influence on the value of $K_{c}(\mathrm{p}<10 \mathrm{E}-11)$ in Ftest among other parameters and their respective interactions (Table 3). Surprisingly, neither the pore size nor the applied pressure demonstrated a statistically significant $(p>0.05)$ effect on the values of the measured cake fouling constants (at least for the applied conditions in this study). The reason for such a significant influence of MLSS on fouling processes in DMs can be 
explained by analysing the primary assumptions of cake filtration model [17], where $K_{c}$ is defined by the following expression:

$$
K_{c}=\frac{\alpha \gamma s \mu}{A^{2} P(1-m s)}
$$

Where, $\alpha$ is the specific cake resistance, $\gamma$ is the filtrate density, $s$ is the mass fraction of solids in the filtrate, $\mu$ is filtrate viscosity, $A$ is the surface area, $P$ is the TMP and $m$ is the mass ratio wet/dry of the cake. The MLSS concentration or mass fraction of solids in the filtrate has a dual effect on the value of $K_{c}$ : a direct proportional effect expressed by the parameter $s$, and an indirect one by influencing other factors involved in the expression such as $\alpha, \gamma$ and $m$.

As far as the TMP is concerned, no significant effect $(\mathrm{p}>0.05)$ was found on the value of $K_{c}$. However, the interaction of MLSS concentration and TMP was significant $(p=0.003$ for MLSS*TMP), demonstrating that the relationship between MLSS and $K_{c}$ also depends on the applied TMP (Table 3).

Pore size, therefore, does not significantly affect $J$ trends during cake filtration (at least using $K_{c}$ values). This clearly demonstrated that the filtration by DMs is exclusively carried out by the cake layer while the mesh only acts as supporting material.

ANOVA performed on final $J$ (i.e. measured after $5 \mathrm{~h}$ filtration) confirms, once again, that MLSS is the only statistically significant parameter characterising DM development, at least under the applied operating conditions of this study (Table S2, Supplementary materials). In addition, it is of note that the final $J$ values were not statistically affected by the combined MLSS*TMP parameter, suggesting that the cake fouling constant $\left(K_{c}\right)$ better reassumes the fouling phenomenon than a specific $J$ values.

Liu et al. [7] proposed a four-stage formation mechanism of DMs over silk mesh, since they observed the progressive development of DM which was characterised by the four classic filtration models occurring sequentially. Li et al. [6], on the contrary, proposed a two-stage 
model to describe the cake formation and flux decline in DM operation by using different mesh filters and under varying operating conditions. They proposed standard blocking as the governing mechanism during the initial stage of filtration whereas the complete blocking and cake filtration dominated in the final stage. This study, on the contrary, demonstrates that cake filtration can adequately describe the $J$ behaviour during DM formation and filtration at least during short-term experiments and under the applied operating conditions.

\subsection{Effluent quality and suspended solids rejection}

Dynamic membrane development was very rapid under all experimental conditions during this study (See Section 3.1) thus resulting in an effluent quality that improved quickly both in terms of turbidity and TSS concentration (Figure 5 and Figure S3, supplementary material). Moreover, during filtration, the effluent turbidity decreased more rapidly than did the permeate flux (Figures 2, 5). In fact, while $J$ decreased to $2 \%$ of the initial values $\left(J_{0}\right)$ in $5 \mathrm{~h}$ (see Section 3.1 ), solids rejection was usually higher than $99 \%$ after only 8 minutes of filtration, corresponding to values typically less than 100 NTU and $20 \mathrm{mg} / \mathrm{L}$ for turbidity (Figure 5) and TSS (Figure S3, supplementary materials). Furthermore, whereas $J$ continuously decreased during the filtration phase, NTU values seemed to show almost stable values after the first few minutes.

The effect of MLSS on effluent turbidity can be observed from Figure 5. The results demonstrate that the lowest effluent turbidity values were obtained at lower MLSS concentrations while no clear effects on turbidity can be observed for mesh sizes and TMPs. Turbidity values after 60 minutes of filtration at $4 \mathrm{~g} / \mathrm{L}$ MLSS were well below $20 \mathrm{NTU}$ for the majority of the experiments (Figure 6). The negative impact of high MLSS concentration was also evident from the effluent SS profile (Figure S3, supplementary materials).

ANOVA performed on effluent turbidity values measured after 60 minutes of continuous filtration with respect to varying operating conditions of the experiments confirms that MLSS 
concentration plays a statistically significant role (Table 4). Moreover, contrary to the cake filtration constant $\left(K_{c}\right)$, turbidity was also significantly $(\mathrm{p}=0.08)$ affected by TMP (Table 4$)$. Similar results were obtained by ANOVA on the turbidity values measure at the end of the filtration (i.e. after $5 \mathrm{~h}$ of filtration; Table S3, supplementary materials).

As a general trend, an increase in filtration resistance is followed by a concomitant reduction in effluent fluxes (Figure 2) and improvement in effluent quality (Figure 6) in terms of solids rejection $[2,7]$. A slight deviation from this trend was observed in this study at high MLSS concentration for which filtration resistance tends to follow the expected increasing trend. However, effluent quality was slightly compromised as compared to the quality of the effluent at low MLSS concentration (Figure 6). A plausible reason of lower effluent quality at high MLSS concentration could be the presence of higher number of smaller sludge particles per unit volume at high MLSS concentrations and thus, chances of these particles passing through the fouling layer acting as a DM are higher at high MLSS concentrations.

High TMP, although not affecting the DM development (at least taken alone as indicated by ANOVA on $J$ and $K_{c}$ ), increases the drag force on the cake layer removing loosely bounded particles by carrying them through the mesh and causes, thus, an increase in effluent turbidity. Moreover, although DM can be formed more rapidly using higher MLSS concentration as suggested by lower fluxes and higher $K_{c}$ values (Figures 2-3), it also caused an increases of the effluent TSS concentration as well as turbidity due to the higher amount of material that can be pushed across the developing DM.

Very surprisingly, the effluent turbidity was not affected by the pore size after the formation of DM (Table 4) confirming once more the negligible effect of the mesh pore size (from 10 to 200 $\mu \mathrm{m})$ on cake filtration by DMs. 


\section{Conclusions}

The results of short term filtration experiments performed in this study using anaerobic sludge at varying operating conditions of MLSS, TMP and mesh pore size can be summarised under the following conclusions:

- $\quad$ DM development under constant pressure was very rapid (less than 5 minutes) and was mainly attributed to very high filtration fluxes observed at the beginning of every experiment. - Initial filtration fluxes ranged from 329 to $9880 \mathrm{Lm}^{-2} \mathrm{~h}^{-1}$ and were followed by much lower fluxes after the formation of the DM.

- MLSS concentration was found to be the major factor affecting the filtration performance of DMs. Fluxes increased at decreasing MLSS. The relationship between MLSS and $K c$ also depends on the applied TMP. On the contrary, pore size (in the range used in this study) did not significantly affect DM development and $J$.

- $\quad$ The cake filtration mechanism can be effectively used to model DM formation and fluxes behaviour.

- Turbidity reduction was very rapid and concomitant to DM development as a result of which, suspended solid removal was usually higher than $99 \%$ within 10 minutes of filtration. Effluent quality in terms of turbidity was negatively related to MLSS concentration and TMP, while was not affected by mesh pore size.

\section{Acknowledgments}

Mubashir Saleem gratefully acknowledges the financial support from Fondazione Cassa di Risparmio di Padova e Rovigo (CARIPARO). 


\section{References}

[1] P. Le-Clech, Membrane bioreactors and their uses in wastewater treatments, Appl. Microbiol. Biot. 88 (2010) 1253-1260.

[2] L. Alibardi, R. Cossu, M. Saleem, A. Spagni, Development and permeability of a dynamic membrane for anaerobic wastewater treatment, Bioresource Technol. 161 (2014) 236-244. [3] Y. Zhang, Y. Zhao, H. Chu, B. Dong, X. Zhou, Characteristics of dynamic membrane filtration: structure, operation mechanisms, and cost analysis, Chinese Sci. Bull. 59 (2014) 247260.

[4] M.E. Ersahin, H. Ozgun, R.K. Dereli, I. Ozturk, K. Roest, J.B. van Lier, A review on dynamic membrane filtration: materials, applications and future perspectives, Bioresource Technol. 122 (2012) 196-206.

[5] X. Zhang, Z. Wang, Z. Wu, F. Lu, J. Tong, L. Zang, Formation of dynamic membrane in an anaerobic membrane bioreactor for municipal wastewater treatment, Chem. Eng. J. 165 (2010) $175-183$.

[6] W. W. Li, G. P. Sheng, Y.K. Wang, X.W. Liu, J. Xu, H.Q. Yu, Filtration behaviors and biocake formation mechanism of mesh filters used in membrane bioreactors, Sep. Purif. Technol. 81 (2011) 472-479.

[7] H. Liu, C.Y. Yang, W. Pu, J. Zhang, Formation mechanism and structure of dynamic membrane in the dynamic membrane bioreactor, Chem. Eng. J. 148 (2009) 290-295.

[8] L. Alibardi, N. Bernava, R. Cossu, A. Spagni, Anaerobic dynamic membrane bioreactor for wastewater treatment at ambient temperature, Chem. Eng. J. 284, (2016) 130-138.

[9] C. Loderer, B. Gahleitner, K. Steinbacher, C. Stelzer, W. Fuchs, Dynamic filtration - A novel approach for critical flux determination using different textiles, Sep. Purif. Technol. 120 (2013) 410-414. 
[10] D. Jeison, I. Diaz, J.B. van Lier, Anaerobic membrane bioreactors: are membranes really necessary? Electron. J. Biotechn. 11 (2008) 1-7.

[11] Y. Kiso, Y-J. Jung, T. Ichinari, M. Park, T. Kitao, K-S. Nishimura, Wastewater treatment performance of a filtration bio-reactor equiped with a mesh filter material, Water Res. 34 (2000) 4143-4150.

[12] M.R. Alavi Moghaddam, H. Satoh, T. Mino, Performance of coarse pore filtration activated sludge system, Water Sci. Technol. 46 (2002) 71-76.

[13] M. E. Ersahin, J.B. Gimenez, H. Ozgun, Y. Tao, H. Spanjers, J.B. van Lier, Gas-lift anaerobic dynamic membrane bioreactors for high strength synthetic wastewater treatment: Effect of biogas sparging velocity and HRT on treatment performance, Chem. Eng. J. http://dx.doi.org/10.1016/j.cej.2016.02.003

[14] M.E. Ersahin, H. Ozgun, J.B. van Lier, Effect of support material properties on dynamic membrane filtration performance, Separ. Sci. Technol. 48 (2013) 2263-2269

[15] J. Ma, Z. Wang, Y. Xu, Q. Wang, Z. Wu, A. Grasmick, Organic matter recovery from municipal wastewater by using dynamic membrane separation process, Chem. Eng. J. 219 (2013) 190-199.

[16] W-K. Chang, A.Y-J. Hub, R-Y. Hornga, W-Y. Tzoua, Membrane bioreactor with nonwoven fabrics as solid-liquid separation media for wastewater treatment, Desalination, 202, (2006) 122128.

[17] Hermia, J. 1982. Constant pressure blocking filtration laws-Application to power-law nonNewtonian fluids, T. I. Chem. Eng-Lond 60 (2007) 183-187.

[18] G. Sabia, M. Ferraris, A. Spagni, Model-based analysis of the effect of different operating conditions on fouling mechanisms in a membrane bioreactor, Enviro. Sci. Pollut. R. 23 (2016) $1598-1609$. 
[19] E. Iritani, A review on modelling of pore-blocking behaviours of membranes during pressurized membrane filtration, Dry. Technol. 31 (2013) 146-162.

[20] M Kim. B. Sankararao. S. Lee, C. Yoo, Prediction and Identification of Membrane Fouling Mechanism in a Membrane Bioreactor Using a Combined Mechanistic Model, Ind. Eng. Chem. Res. 52 (2013) 17198-17205.

[21] G. Bolton, D. LaCasse, R. Kuriyel, Combined models of membrane fouling: Development and application to microfiltration and ultrafiltration of biological fluids, J. Membrane. Sci. 277 (2006) 75-84.

[22] Y. Ye, P. Le Cleck, V. Chen, A.G. Fane., B. Jefferson, Fouling mechanisms of alginate solutions as model extracellular polymeric substances, Desalination 175 (2005) 7-20.

[23] M. Saleem, L. Alibardi, M.C. Lavagnolo, R. Cossu, A. Spagni, Effect of filtration flux on the development and operation of a dynamic membrane for anaerobic wastewater treatment. J. Environ. Manage. 180 (2016) 469-465.

[24] S. Liang, L. Qu, F. Meng, X. Han, J. Zhang, Effect of sludge properties on the filtration characteristics of self-forming dynamic membranes (SFDMs) in aerobic bioreactors: Formation time, filtration resistance, and fouling propensity, J. Membrane. Sci. 436 (2013) 186-94.

[25] S. Geissler, U. Werner, Dynamic model of crossflow microfiltration in flat-channel systems under laminar flow conditions, Filtr. Separat. 32 (1995) 533-537.

[26] APHA-AWWA-WEF., 2005. Standard Methods for the Examination of Water and Wastewater, 21st ed., American Public Health Association, American Water Works Association, Water Environment Federation. Washington, D.C.

[27] J. Mendret, C, Guigui, P, Schmitz, C. Cabassud, In situ dynamic characterisation of fouling under different pressure conditions during dead-end filtration: Compressibility properties of particle cakes, J. Membrane. Sci. 333 (2009) 20-29. 
[28] Salerno C., Vergine P., Berardi G., Pollice A., Influence of air scouring on the performance of a self forming dynamic membrane bioreactor (SFD MBR) for municipal wastewater treatment. (2016) In press: http://dx.doi.org/10.1016/J.biortech.2016.10.054.

[29] W.W. Li, Y-K. Wang, J. Xu, Y.R. Tong, L. Zhao, H. Peng, G.P. Sheng, H.Q. Yu, A deadend filtration method to rapidly and quantitatively evaluate the fouling resistance of nylon mesh for membrane bioreactor, Sep. Purif. Technol. 89 (2012)107-111.

[30] J. Ho, S. Sung, Effects of solid concentrations and cross-flow hydrodynamics on microfiltration of anaerobic sludge, J. Membrane. Sci. 345 (2009) 142-147.

[31] M. Lousada-Ferreira J.B. van Lier, J.H.J.M. van der Graaf, Impact of suspended solids concentration on sludge filterability in full-scale membrane bioreactors, J. Membrane. Sci. 476 (2015) 68-75. 


\section{Table captions}

Table 1. Summary of characteristic equations for constant pressure filtration laws proposed by Hermia [17].

Table 2. Properties of the meshes used in this study.

Table 3. Factorial ANOVA for evaluating the effect of MLSS, TMP and mesh pore size on the value of blocking constant for cake filtration model.

Table 4. Factorial ANOVA for evaluating the effect of MLSS, TMP and mesh pore size on effluent turbidity values measured after 60 minutes of continuous filtration.

\section{Figure captions}

Figure 1. Schematic diagram of the experimental setup.

Figure 2. Filtration flux profiles under different operating conditions. Colour for MLSS concentration; Line type for applied pressure; Symbol for mesh pore size Figure 3. Effect of mesh pore size and MLSS concentration on final flux values at (a) $5 \mathrm{kPa}$, (b) $10 \mathrm{kPa}$ and (c) $18 \mathrm{kPa}$.

Figure 4. Curve fittings for the observed flux profiles with Hermia's models at MLSS $4 \mathrm{~g} / \mathrm{L}$, TMP $5 \mathrm{kPa}$ and mesh with $10 \mu \mathrm{m}$ pore size with (lines: predicted data; symbols: experimental results).

Figure 5. Effluent turbidity profiles under different operating conditions. Colour for MLSS concentration; Line type for applied pressure; Symbol for mesh pore size.

Figure 6. Effect of mesh pore size and MLSS concentration on effluent turbidity values after 60 minute of filtration at (a) $5 \mathrm{kPa}$, (b) $10 \mathrm{kPa}$ and (c) $18 \mathrm{kPa}$ 


\section{Supplementary material}

\section{Table captions}

Table S1. Operational conditions applied during filtration experiments.

Table S2. Factorial ANOVA for evaluating the effect of MLSS, TMP and mesh pore size on final flux values.

Table S3. Factorial ANOVA for evaluating the effect of MLSS, TMP and mesh pore size on effluent turbidity values measured after 300 minutes of continuous filtration (i.e. at the end of experiment).

\section{Figure captions}

Figure S1. Adjusted R2 ( $\mathrm{R}^{2}$ adj $)$ values for curve fitting analysis of Hermia's models.

Figure S2. RMSE values for curve fitting analysis of Hermia's models.

Figure S3. Effluent TSS values under different operating conditions applied. Colour for MLSS concentration; Line type for applied pressure; Symbol for mesh pore size. 


\section{Table captions}

Table 1. Summary of characteristic equations for constant pressure filtration laws proposed by Hermia [17].

Table 2. Properties of the meshes used in this study.

Table 3. Factorial ANOVA for evaluating the effect of MLSS, TMP and mesh pore size on the value of blocking constant for cake filtration model.

Table 4. Factorial ANOVA for evaluating the effect of MLSS, TMP and mesh pore size on effluent turbidity values measured after 60 minutes of continuous filtration. 
Table 1. Summary of characteristic equations for constant pressure filtration laws proposed by Hermia [17].

\begin{tabular}{|c|c|c|c|c|}
\hline $\begin{array}{l}\text { Fouling } \\
\text { Mechanism }\end{array}$ & Model & $\begin{array}{l}\text { Blocking } \\
\text { constant }\end{array}$ & $\begin{array}{c}\text { Physical } \\
\text { Description }\end{array}$ & $\begin{array}{l}\text { Schematic } \\
\text { representation }\end{array}$ \\
\hline $\begin{array}{l}\text { Complete } \\
\text { Blocking }\end{array}$ & $J=J_{o} e^{-K_{b} t}$ & $K_{b}$ & $\begin{array}{l}\text { Pore } \\
\text { blocking }\end{array}$ & \\
\hline $\begin{array}{l}\text { Standard } \\
\text { Blocking }\end{array}$ & $J=\frac{J_{o}}{\left(1+\frac{K_{S} J_{o}^{\frac{1}{2}} t}{2}\right)^{2}}$ & $K_{s}$ & $\begin{array}{l}\text { Pore } \\
\text { constriction }\end{array}$ & 8 \\
\hline $\begin{array}{l}\text { Intermediate } \\
\text { Blocking }\end{array}$ & $J=\frac{J_{o}}{\left(1+K_{i} J_{o} t\right)}$ & $K_{i}$ & $\begin{array}{l}\text { Pore } \\
\text { blocking }+ \\
\text { surface } \\
\text { deposition }\end{array}$ & \\
\hline $\begin{array}{l}\text { Cake } \\
\text { Filtration }\end{array}$ & $J=\frac{J_{o}}{\left(1+2 K_{c} J_{o}{ }^{2} t\right)^{\frac{1}{2}}}$ & $K_{c}$ & $\begin{array}{l}\text { Surface } \\
\text { deposition }\end{array}$ & \\
\hline
\end{tabular}


Table 2. Properties of the meshes used in this study.

\begin{tabular}{|c|c|c|c|c|c|c|}
\hline $\begin{array}{r}\text { Product } \\
\text { information }\end{array}$ & $\begin{array}{c}\text { Mesh } \\
\text { opening } \\
(\mu \mathrm{m})\end{array}$ & $\begin{array}{l}\text { Open } \\
\text { area } \\
(\%)\end{array}$ & $\begin{array}{l}\text { Mesh } \\
\text { count } \\
(/ \mathrm{cm})\end{array}$ & $\begin{array}{l}\text { Thread } \\
\text { diameter } \\
(\mu \mathrm{m})\end{array}$ & $\begin{array}{c}\text { Resistance } \\
\text { (Clean } \\
\text { mesh) }(1 / \mathrm{m} \text { - } \\
\text { 1) } \\
\text { (2) }\end{array}$ & $\begin{array}{c}\text { Tap water } \\
\text { permeability } \\
(\mathrm{L} / \mathrm{m} 2 . \mathrm{h}-1 . \mathrm{kPa}-1)^{(3)}\end{array}$ \\
\hline SaatiMil PA ${ }^{(1)} 7$ & 200 & 39 & 31 & 120 & $5.46 \times 10^{9}$ & 1572.3 \\
\hline SaatiMil PA 10 & 135 & 39 & 46 & 80 & $5.37 \times 10^{9}$ & 1597.7 \\
\hline SaatiMil PA 15 & 85 & 49 & 81 & 37 & $5.42 \times 10^{9}$ & 1583.2 \\
\hline $\begin{array}{l}\text { Saatifil PA } \\
52 / 32\end{array}$ & 52 & 32 & 110 & 38 & $5.61 \times 10^{9}$ & 1528.6 \\
\hline Saatifil PA 10/4 & 10 & 4 & $\begin{array}{l}200 x \\
220\end{array}$ & $30 \times 38$ & $6.46 \times 10^{9}$ & 1328.4 \\
\hline
\end{tabular}

(1) PA is an acronym for polyamide

(2) Resistance of the mesh measured at TMP of $5 \mathrm{kPa}$

(3) $20{ }^{\circ} \mathrm{C}$ normalised permeability measured at TMP of $5 \mathrm{kPa}$ 
Table 3. Factorial ANOVA for evaluating the effect of MLSS, TMP and mesh pore size on the value of blocking constant for cake filtration model.

\begin{tabular}{ccccc}
\hline Parameters & Sum of & Mean square & F & P \\
& square & & & \\
\hline MLSS & $1.510 \mathrm{E}-06$ & $7.552 \mathrm{E}-07$ & 185.961 & $<10 \mathrm{E}-11$ \\
TMP & $6.427 \mathrm{E}-09$ & $3.213 \mathrm{E}-09$ & 0.791 & 0.470 \\
Pore size & $4.132 \mathrm{E}-08$ & $1.033 \mathrm{E}-08$ & 2.544 & 0.080 \\
MLSS x TMP & $1.056 \mathrm{E}-07$ & $2.641 \mathrm{E}-08$ & 6.504 & 0.003 \\
MLSS x Pore size & $2.153 \mathrm{E}-08$ & $2.691 \mathrm{E}-09$ & 0.663 & 0.716 \\
TMP x Pore size & $6.545 \mathrm{E}-08$ & $8.181 \mathrm{E}-09$ & 2.015 & 0.111 \\
\hline
\end{tabular}


Table 4. Factorial ANOVA for evaluating the effect of MLSS, TMP and mesh pore size on effluent turbidity values measured after 60 minutes of continuous filtration.

\begin{tabular}{ccccc}
\hline Parameters & Sum of & Mean square & F & P \\
& square & & & \\
\hline MLSS & 5835.006 & 2917.503 & 7.787 & 0.004 \\
TMP & 4923.811 & 2461.905 & 6.571 & 0.008 \\
Pore size & 3631.665 & 907.916 & 2.423 & 0.091 \\
MLSS x TMP & 2694.338 & 673.585 & 1.798 & 0.179 \\
MLSS x Pore size & 2977.771 & 372.221 & 0.993 & 0.477 \\
TMP x Pore size & 3369.520 & 421.190 & 1.124 & 0.399 \\
\hline
\end{tabular}




\section{Figure captions}

Figure 1. Schematic diagram of the experimental setup.

Figure 2. Filtration flux profiles under different operating conditions. Colour for MLSS concentration; Line type for applied pressure; Symbol for mesh pore size.

Figure 3. Effect of mesh pore size and MLSS concentration on final flux values at (a) $5 \mathrm{kPa}$, (b) $10 \mathrm{kPa}$ and (c) $18 \mathrm{kPa}$.

Figure 4. Curve fittings for the observed flux profiles with Hermia's models at MLSS $4 \mathrm{~g} / \mathrm{L}$, TMP $5 \mathrm{kPa}$ and mesh with $10 \mu \mathrm{m}$ pore size with (lines: predicted data; symbols: experimental results).

Figure 5. Effluent turbidity profiles under different operating conditions. Colour for MLSS concentration; Line type for applied pressure; Symbol for mesh pore size.

Figure 6. Effect of mesh pore size and MLSS concentration on effluent turbidity values after 60 minute of filtration at (a) $5 \mathrm{kPa}$, (b) $10 \mathrm{kPa}$ and (c) $18 \mathrm{kPa}$. 


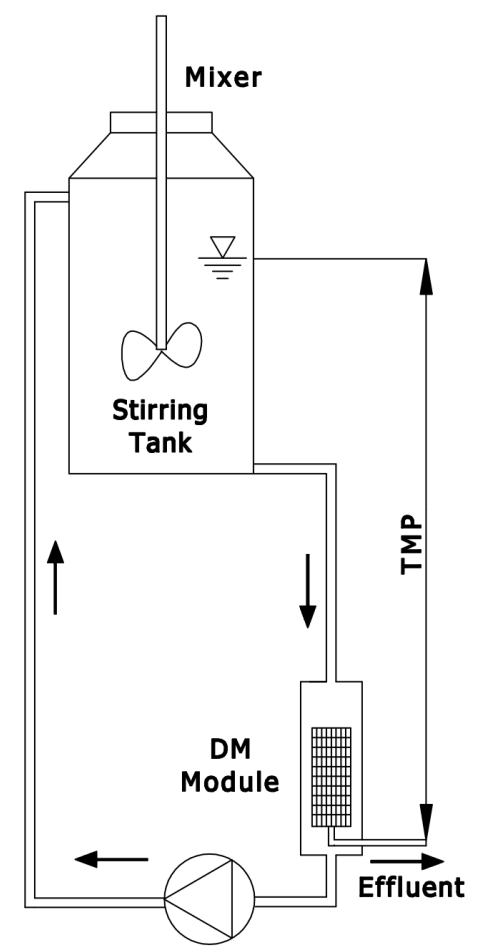

Figure 1. Schematic diagram of the experimental setup. 


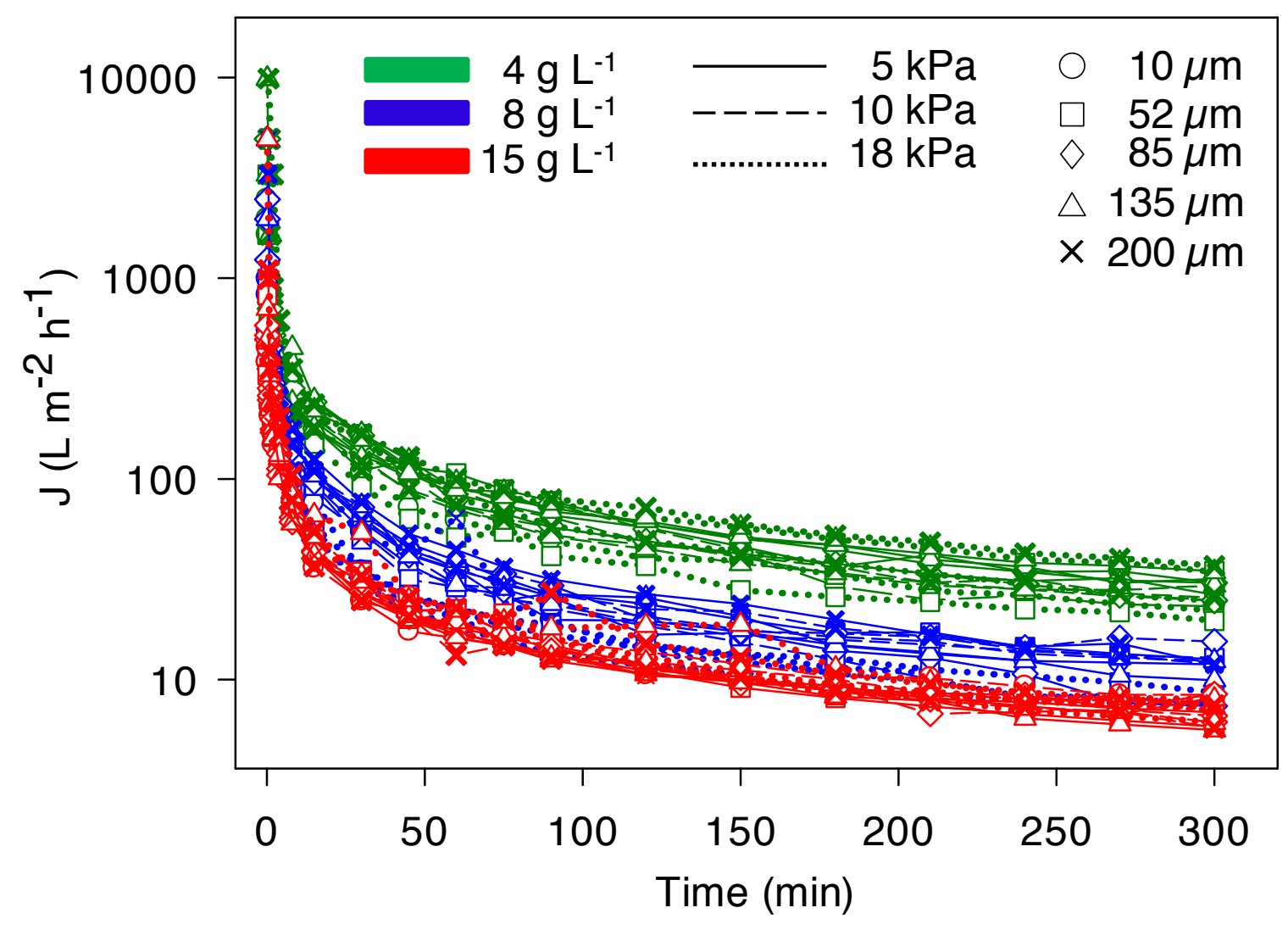

Figure 2. Filtration flux profiles under different operating conditions. Colour for MLSS concentration; Line type for applied pressure; Symbol for mesh pore size. 

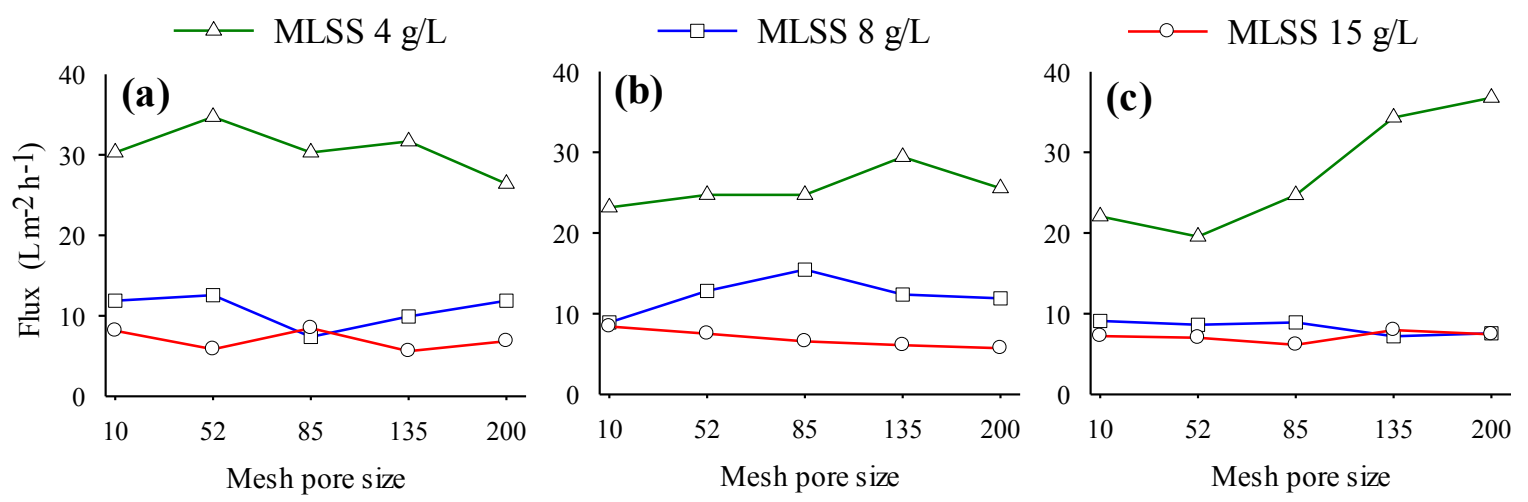

Figure 3. Effect of mesh pore size and MLSS concentration on final flux values at (a) $5 \mathrm{kPa}$, (b) $10 \mathrm{kpa}$ and (c) $18 \mathrm{kP}$ 


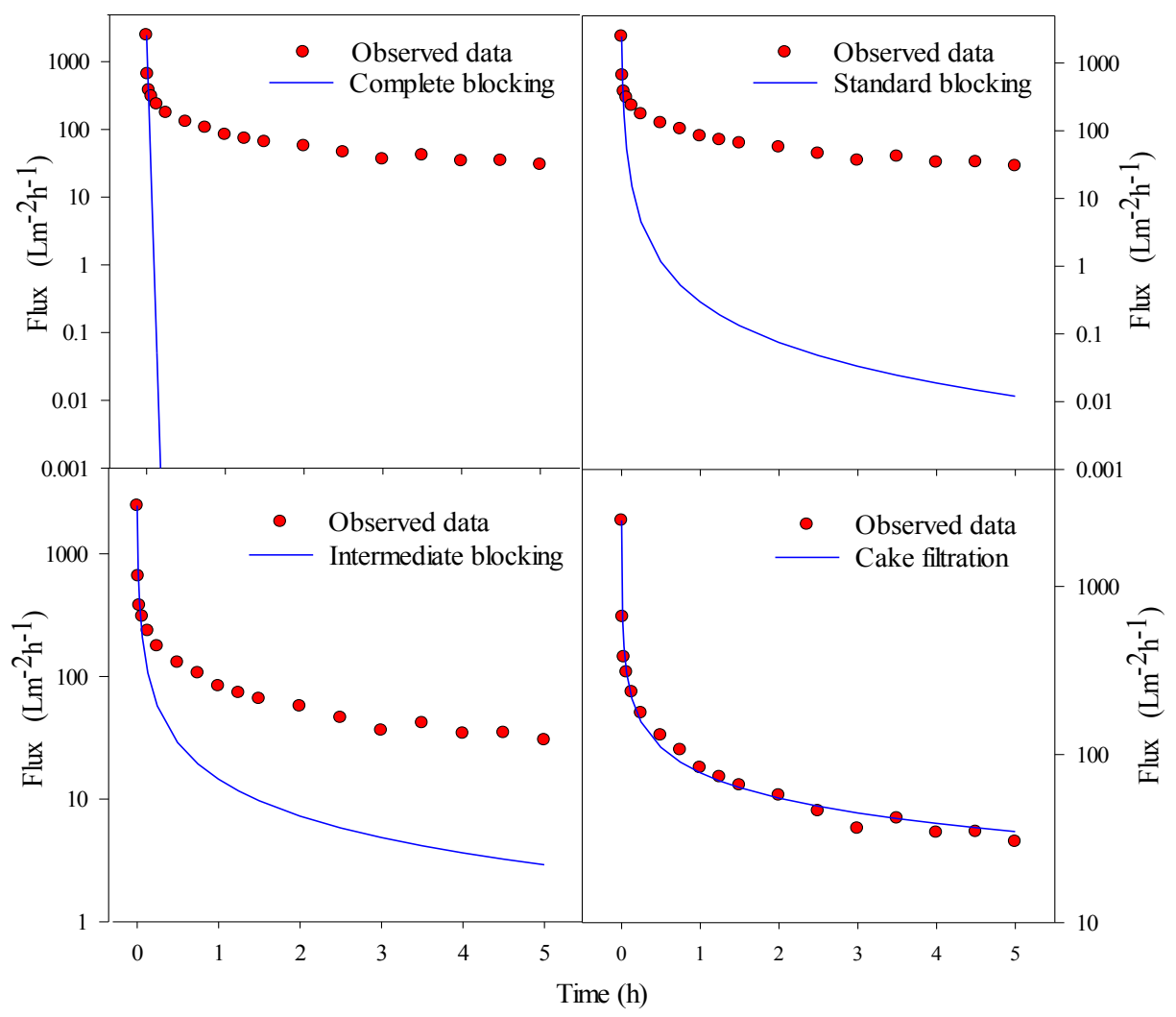

Figure 4. Curve fittings for the observed flux profiles with Hermia's models at MLSS $4 \mathrm{~g} / \mathrm{L}$, TMP $5 \mathrm{kPa}$ and mesh with $10 \mu \mathrm{m}$ pore size with (lines: predicted data; symbols: experimental results). 


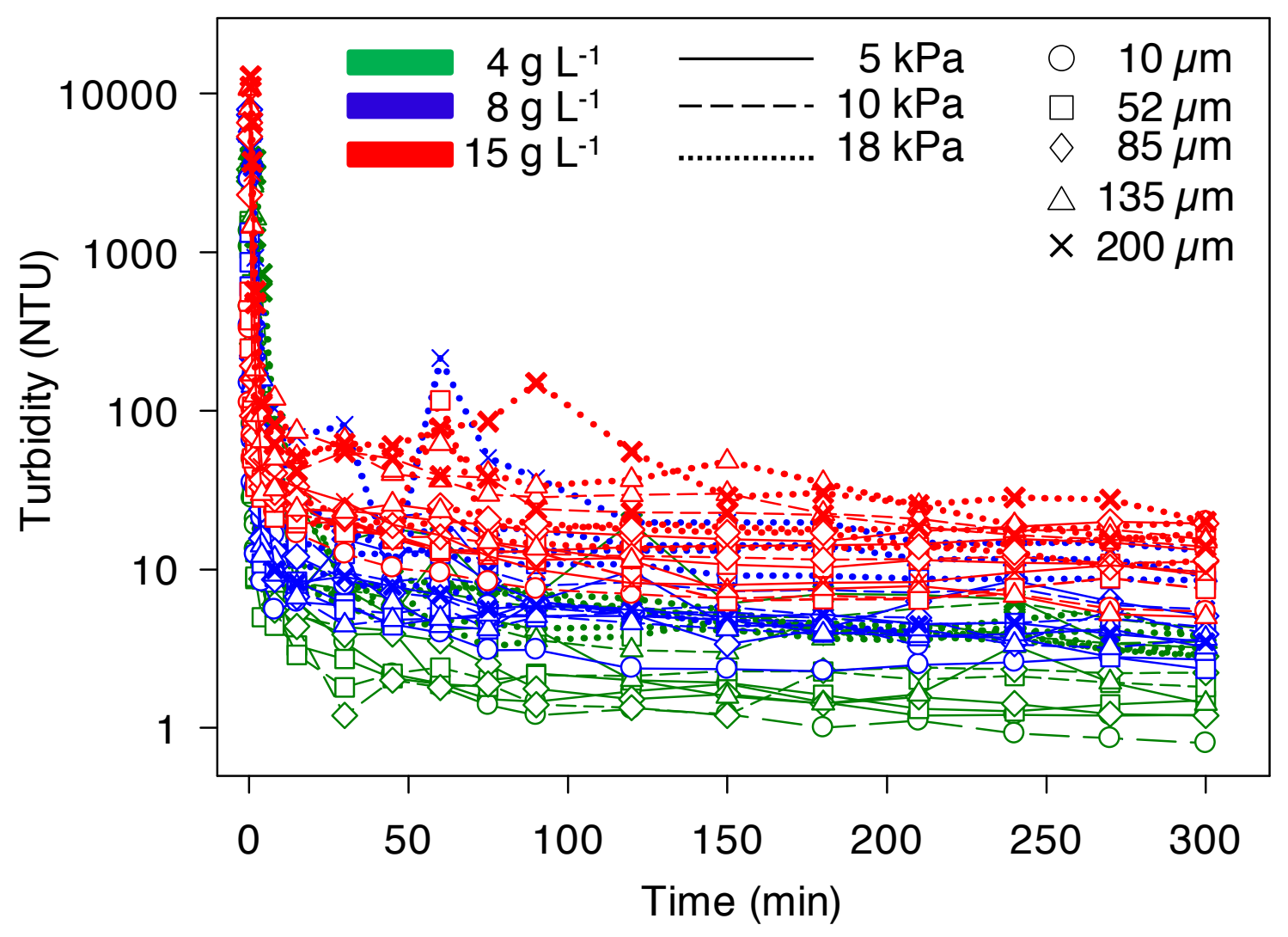

Figure 5. Effluent turbidity profiles under different operating conditions. Colour for MLSS concentration; Line type for applied pressure; Symbol for mesh pore size. 

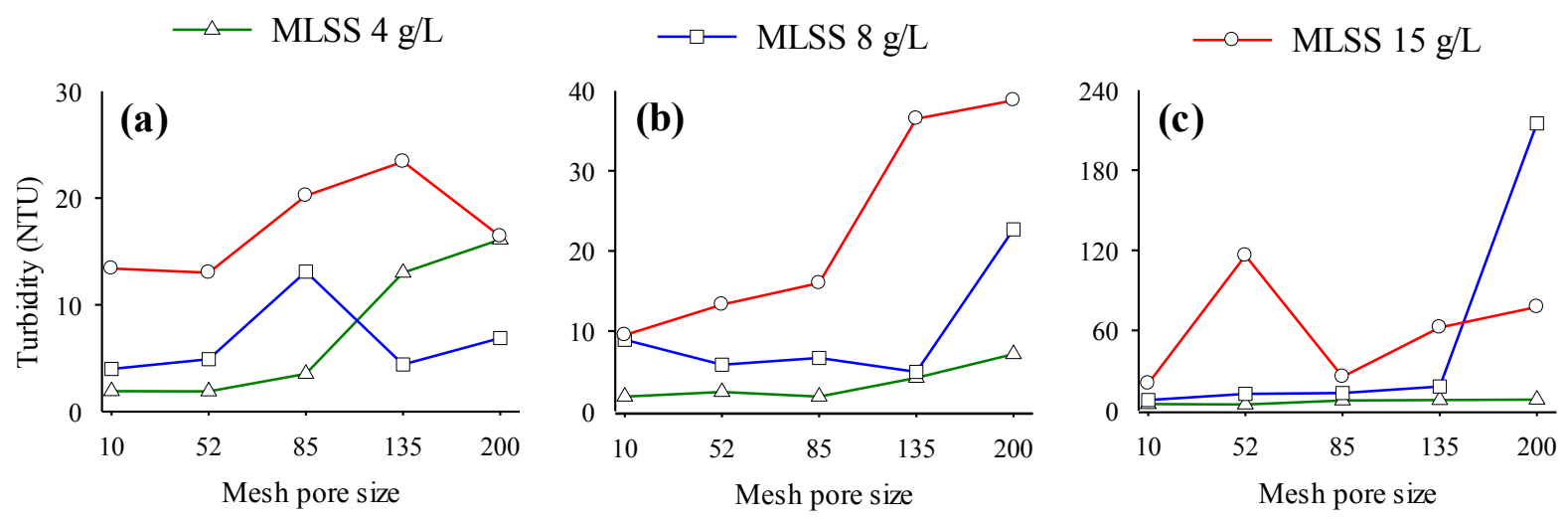

Figure 6. Effect of mesh pore size and MLSS concentration on effluent turbidity values after 60 minute of filtration at (a) $5 \mathrm{kPa}$, (b) $10 \mathrm{kpa}$ and (c) $18 \mathrm{kPa}$. 


\section{Supplementary material}

\section{Table captions}

Table S1. Operational conditions applied during filtration experiments.

Table S2. Factorial ANOVA for evaluating the effect of MLSS, TMP and mesh pore size on final flux values.

Table S3. Factorial ANOVA for evaluating the effect of MLSS, TMP and mesh pore size on effluent turbidity values measured after 300 minutes of continuous filtration (i.e. at the end of experiment).

\section{Figure captions}

Figure $\mathrm{S} 1$. Adjusted R2 ( $\left.{ }^{2}{ }_{\text {adj }}\right)$ values for curve fitting analysis of Hermia's models.

Figure S2. RMSE values for curve fitting analysis of Hermia's models.

Figure S3. Effluent TSS values under different operating conditions applied. Colour for MLSS concentration; Line type for applied pressure; Symbol for mesh pore size. 
Table S1. Operational conditions applied during filtration experiments.

\begin{tabular}{|c|c|c|c|}
\hline $\begin{array}{c}\text { Experiment } \\
\text { Number }\end{array}$ & $\begin{array}{l}\text { MLSS } \\
(\mathrm{g} / \mathrm{L})\end{array}$ & $\begin{array}{c}\text { PORE } \\
\text { SIZE }(\mu \mathrm{m})\end{array}$ & $\begin{array}{l}\text { TMP } \\
\text { (kPa) }\end{array}$ \\
\hline $1,2,3$ & 4 & 10 & $5,10,18$ \\
\hline $4,5,6$ & 4 & 52 & $5,10,18$ \\
\hline $7,8,9$ & 4 & 85 & $5,10,18$ \\
\hline $10,11,12$ & 4 & 135 & $5,10,18$ \\
\hline $13,14,15$ & 4 & 200 & $5,10,18$ \\
\hline $16,17,18$ & 8 & 10 & $5,10,18$ \\
\hline $19,20,21$ & 8 & 52 & $5,10,18$ \\
\hline $22,23,24$ & 8 & 85 & $5,10,18$ \\
\hline $25,26,27$ & 8 & 135 & $5,10,18$ \\
\hline $28,29,30$ & 8 & 200 & $5,10,18$ \\
\hline $31,32,33$ & 15 & 10 & $5,10,18$ \\
\hline $34,35,36$ & 15 & 52 & $5,10,18$ \\
\hline $37,38,39$ & 15 & 85 & $5,10,18$ \\
\hline $40,41,42$ & 15 & 135 & $5,10,18$ \\
\hline $43,44,45$ & 15 & 200 & $5,10,18$ \\
\hline
\end{tabular}


Table S2. Factorial ANOVA for evaluating the effect of MLSS, TMP and mesh pore size on final flux values.

\begin{tabular}{ccccc}
\hline Parameters & Sum of & Mean square & F & P \\
& square & & & \\
\hline MLSS & 3771.906 & 1885.953 & 180.387 & $<10 \mathrm{E}-10$ \\
TMP & 26.827 & 13.414 & 1.283 & 0.304 \\
Pore size & 17.336 & 4.334 & 0.415 & 0.796 \\
MLSS x TMP & 85.800 & 21.450 & 2.052 & 0.135 \\
MLSS x Pore size & 79.254 & 9.907 & 0.948 & 0.507 \\
TMP x Pore size & 80.453 & 10.057 & 0.962 & 0.497 \\
\hline
\end{tabular}


Table S3. Factorial ANOVA for evaluating the effect of MLSS, TMP and mesh pore size on effluent turbidity values measured after 300 minutes of continuous filtration (i.e. at the end of experiment).

\begin{tabular}{ccccc}
\hline Parameters & Sum of & Mean square & F & P \\
& square & & & \\
\hline MLSS & 5748.361 & 2874.181 & 5.292 & 0.017 \\
TMP & 6011.720 & 3005.860 & 5.535 & 0.015 \\
Pore size & 4839.088 & 1209.772 & 2.228 & 0.112 \\
MLSS x TMP & 2940.163 & 735.041 & 1.353 & 0.294 \\
MLSS x Pore size & 4309.949 & 538.744 & 0.992 & 0.478 \\
TMP x Pore size & 4834.278 & 604.285 & 1.113 & 0.405 \\
\hline
\end{tabular}




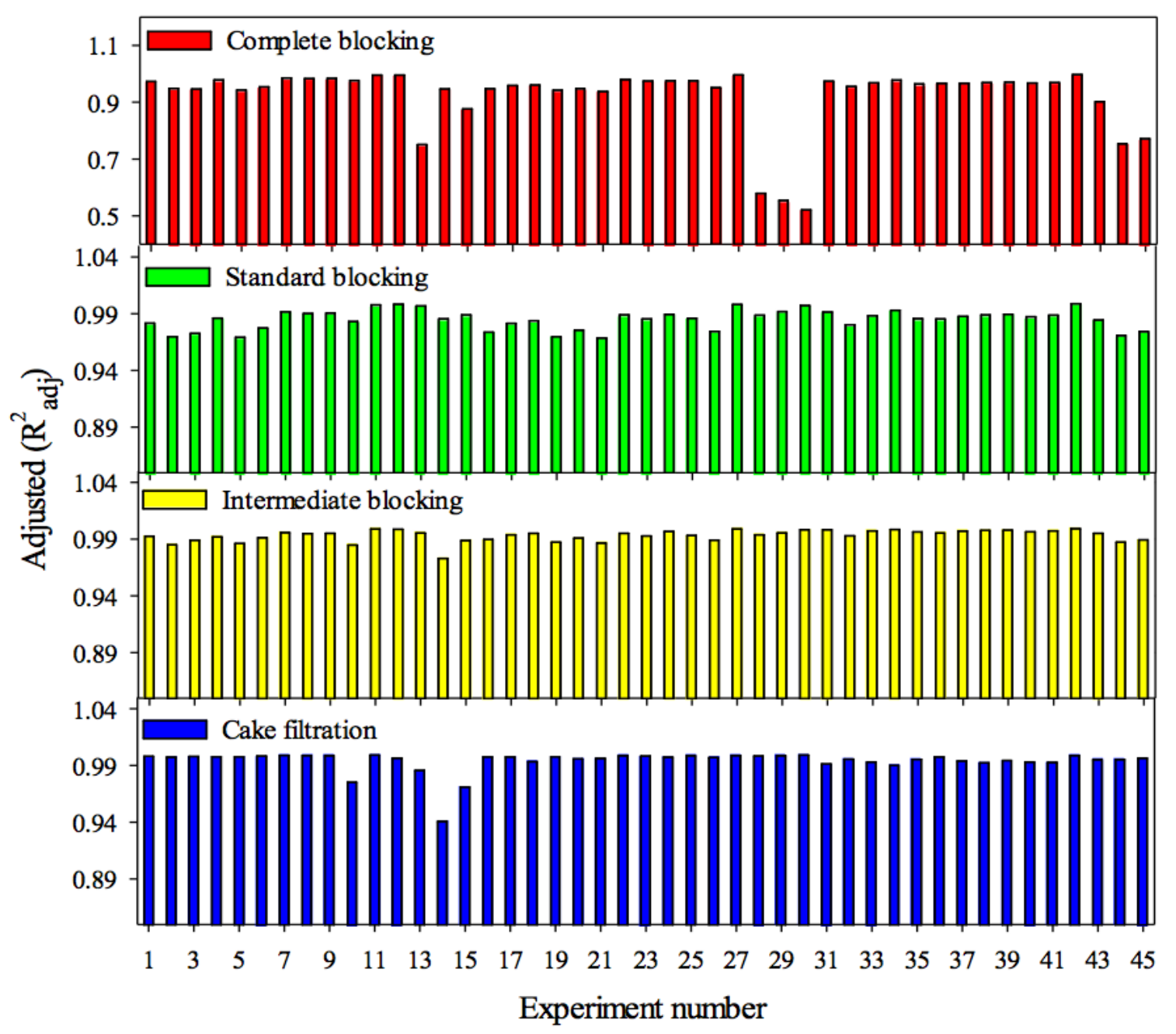

Figure S1. Adjusted R2 ( $\left.\mathrm{R}_{\text {adj }}^{2}\right)$ values for curve fitting analysis of Hermia's models. 


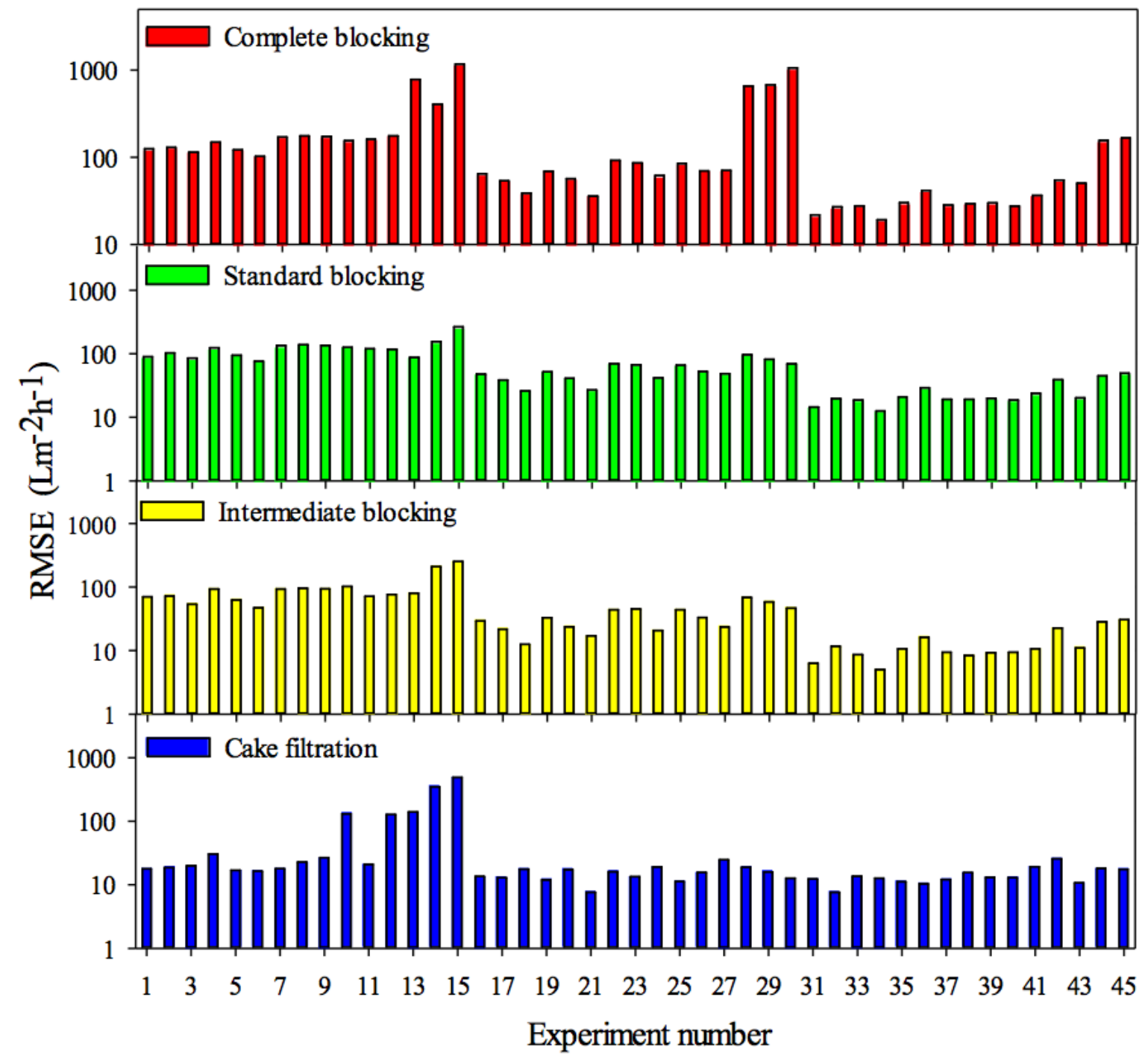

Figure S2. RMSE values for curve fitting analysis of Hermia's models. 


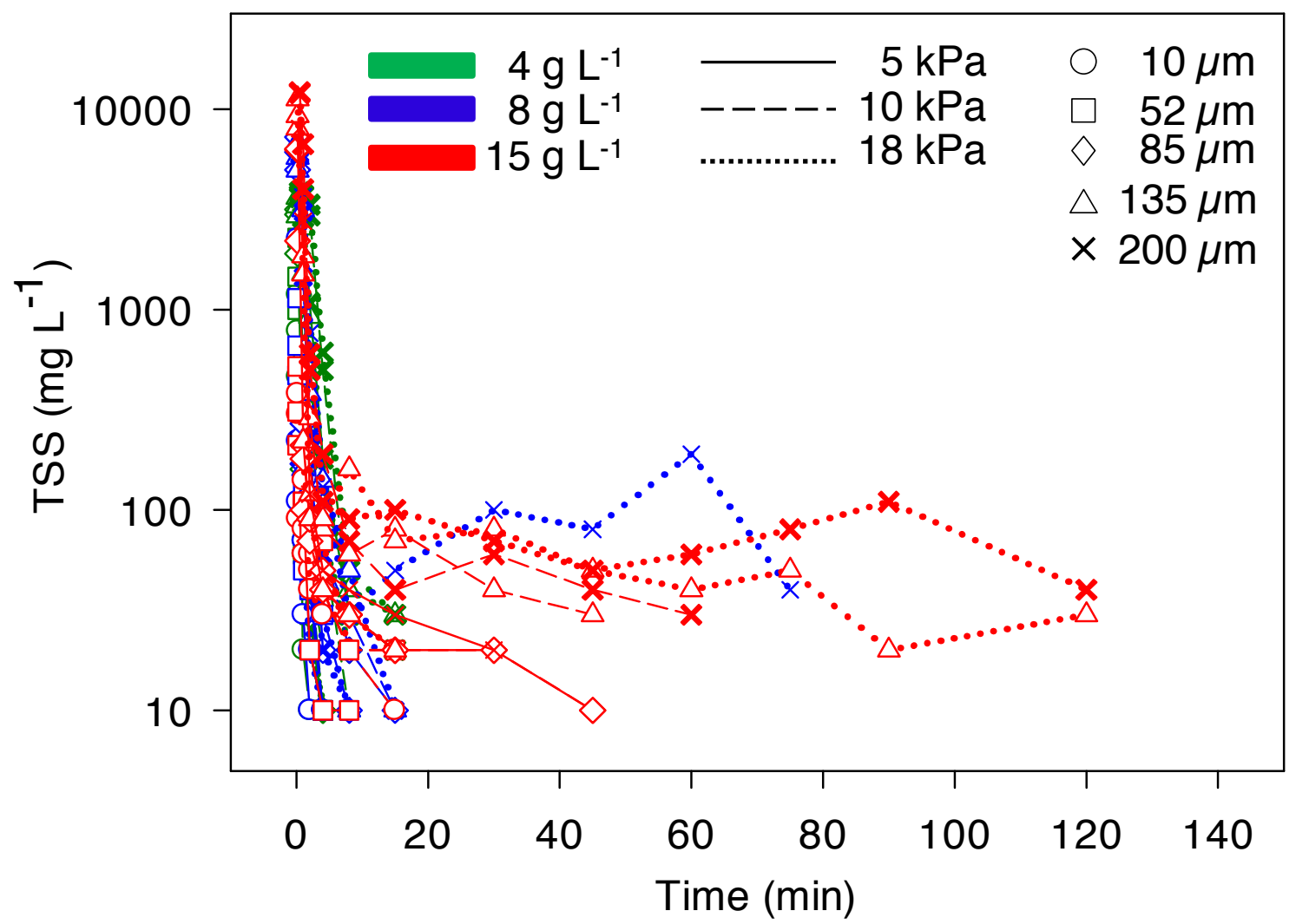

Figure S3. Effluent TSS values under different operating conditions applied. Colour for MLSS concentration; Line type for applied pressure; Symbol for mesh pore size. 